\title{
Emergência, crescimento e produção da mamoneira sob estresse salino e adubação nitrogenada ${ }^{1}$
}

\author{
Emergence, growth and production of the castor bean under saline stress and nitrogen \\ fertilization
}

\author{
Reginaldo Gomes Nobre ${ }^{2 *}$, Geovani Soares de Lima ${ }^{3}$, Hans Raj Gheyi ${ }^{4}$, Givanildo da Silva Lourenço ${ }^{5}$ Lauriane \\ Almeida dos Anjos Soares ${ }^{3}$
}

\begin{abstract}
RESUMO - O uso de água salina na atividade agrícola vem se tornando uma realidade em diversas regiões do mundo, tendo em vista o aumento na demanda por água doce, tanto para agricultura irrigada, como no abastecimento urbano e industrial. Neste sentido, objetivou-se com esta pesquisa avaliar o efeito de diferentes níveis de salinidade da água de irrigação associada a doses de adubação nitrogenada, sobre a emergência, crescimento e produção da mamoneira cv. BRS Energia, em experimento onde as plantas foram conduzidas em lisímetros sob condições de campo, no CCTA/UFCG. Utilizou-se a aleatoriedade em bloco em esquema fatorial 5 x 5 , com três repetições, sendo estudados os efeitos de cinco níveis de condutividade elétrica da água de irrigação $\left(0,4 ; 1,4 ; 2,4 ; 3,4\right.$ e $\left.4,4 \mathrm{dS} \mathrm{m}^{-1}\right)$ associados a cinco doses de adubação nitrogenada $(50 ; 75 ; 100 ; 125$ e $150 \%$ da dose recomendada para ensaios em vaso). A salinidade da água de irrigação a partir de $0,4 \mathrm{dS} \mathrm{m}^{-1}$ afeta linear e negativamente a percentagem de emergência (PE), o índice de velocidade de emergência (IVE), a altura de planta (AP), o diâmetro caulinar (DC), a fitomassa seca da parte aérea (FSPA) e de raiz (FSRaiz) e a massa de sementes do racemo primário (MSemRP), enquanto que doses crescentes de nitrogênio promoveram aumento no DC, na FSPA e na FSRaiz. A aplicação de doses crescentes de N reduziu o efeito da salinidade sobre o DC e a FSRaiz da mamoneira cv. BRS Energia.
\end{abstract}

Palavras-chave: Mamona. Plantas-efeito do sal. Adubação nitrogenada.

\begin{abstract}
The use of saline water in agriculture is becoming a reality in many regions of the world, given the increased demand for fresh water, both for irrigated agriculture, as well as for urban and industrial supply. In this context, the aim of this research was to evaluate the effect of different salinity levels in irrigation water, associated with amounts of nitrogen fertilizer, on the emergence, growth and yield of the castor bean, cv. BRS Energia, in an experiment where plants were maintained in lysimeters under field conditions, at the CCTA/ UFCG. A randomised block design in a 5 x 5 factorial with three replications was used to study the effects of five levels of electrical conductivity of the irrigation water $\left(0.4,1.4,2.4,3.4\right.$ and $\left.4.4 \mathrm{dS} \mathrm{m}^{-1}\right)$ associated with five levels of nitrogen fertilizer $(50,75,100,125$ and $150 \%$ of the dose recommended for testing in pots). The salinity of the irrigation water from $0.4 \mathrm{dS} \mathrm{m}^{-1}$ affects negatively and in a linear manner the percentage of emergence (PE), the emergence speed index (IVE), plant height (AP), the stem diameter (DC), the shoot dry-weight (FSPA) and root dry-weight (FSRaiz) and the seed mass of the primary raceme (MSemRP), whereas increasing levels of nitrogen caused an increase in DC, FSPA and FSRaiz. The application of increasing doses of $\mathrm{N}$ reduced the effect of salinity on the DC and FSRaiz of the castor bean cv. BRS Energia.
\end{abstract}

Key words: Castor bean. Plants-effect of salt. Nitrogen fertilizer.

\footnotetext{
*Autor para correspondência

Recebido para publicação em 06/09/2011; aprovado em 02/07/2012

Parte do trabalho financiado pelo CNPq/Edital Universal

${ }^{2}$ Centro de Ciências e Tecnologia Agroalimentar, Unidade Acadêmica de Ciências Agrárias, Universidade Federal de Campina Grande, Rua Newton Seixas, 333, Jardim Rogério, Pombal-PB, Brasil, 58.840-000, rgomesnobre@yahoo.com.br

${ }^{3}$ Departamento de Engenharia Agrícola/UAEA/UFCG, Campina Grande-PB, Brasil, geovanisoareslima@ gmail.com, laurispo@hotmail.com

${ }^{4}$ Núcleo de Engenharia de Água e Solo, Universidade Federal do Reconcavo da Bahia/UFRB, Cruz das Almas-BA, Brasil, hans @ pq.cnpq.br

${ }^{5}$ Unidade Acadêmica de Ciências Agrárias/UAGRA/UFCG, Pombal-PB, Brasil, givanildo83@ r7.com
} 


\section{INTRODUÇÃO}

A escassez dos recursos hídricos nas regiões áridas e semiáridas envolve aspectos quantitativos e qualitativos, causando restrições de uso para o consumo humano, animal e irrigação (MEDEIROS et al., 2003). Nessas regiões, é também comum a ocorrência de fontes de água com elevada concentração de sais e principalmente o sódio - dois fatores que reduzem a qualidade desse recurso para utilização na agricultura (NEVES et al., 2009). Aliado a isto, no semiárido a pluviosidade baixa e a evapotranspiração elevada contribuem decisivamente para o agravamento da salinização dos solos (VIÉGAS et al., 2001).

As plantas quando cultivadas sob condições de salinidade de solo ou da água de irrigação podem ter o crescimento, o desenvolvimento e a produção comprometidas devido ao efeito osmótico, que reduz a absorção de água pela planta e/ou em função do efeito específico dos íons que causam distúrbios funcionais e injúrias principalmente nas folhas, afetando assim, o metabolismo das plantas. No entanto, o grau com que o estresse salino irá afetar as plantas vai depender principalmente da tolerância da cultura à salinidade, do manejo da irrigação e adubação e dos fatores climáticos locais (MUNNS, 2005; SILVA et al., 2003).

A nutrição mineral é um importante fator ambiental, sendo o nitrogênio o macronutriente exigido em maior quantidade pelas culturas agrícolas (MILLER; CRAMER, 2004). Conforme Chaves, Gheyi e Ribeiro (2011), a adubação é uma das principais tecnologias usadas visando o aumento da produtividade e da rentabilidade das culturas, onde entre estas, pode-se citar a mamoneira (Ricinus communis L.), sendo o nitrogênio, um dos principais responsáveis por esse aumento.

Segundo Fageria (1989), o mais importante mecanismo para regular o estresse osmótico, talvez seja a absorção seletiva de íons, pois plantas tolerantes possuem a capacidade de retirar nutrientes essenciais tais como $\mathrm{K}^{+}$e $\mathrm{Ca}^{++}$da solução salina, onde a concentração de íons não essenciais (tóxicos) é maior. Kafkafi (1984) relata que existem evidências de competição na absorção entre nitrato e cloreto, de modo que um aumento na concentração de nitrato na zona radicular pode inibir uma maior absorção de cloreto pela planta.

A crise mundial em decorrência da demanda energética, visando à substituição dos combustíveis fósseis, tem incrementado a busca por fontes alternativas e limpas de energia, nos últimos anos, priorizado fontes renováveis que não causem impacto negativo ao meio ambiente. Dentre as alternativas, destaca-se a mamoneira devido à possibilidade do uso de seu óleo como biodiesel (CAVALCANTI et al., 2005a).
A mamoneira pertence à família Euphorbiaceae, sendo atualmente cultivada em diversos países do mundo, destacando-se a Índia, a China e o Brasil como os maiores produtores mundiais. Seu óleo é um dos melhores para a produção de biodiesel pelas suas características como maior densidade, solubilidade em álcool, e usos na química em mais de 700 produtos (BELTRÃO et al., 2003; MARINHO et al., 2010).

Apesar da mamoneira ser uma espécie adaptada à condição de semiaridez, a garantia de produção deverá ser maior com o uso da irrigação (DINIZ NETO et al., 2009), não havendo, atualmente, na literatura, qualquer indicação da exigência hídrica e nutricional das plantas e/ou do efeito de águas de qualidade inferior sobre seu cultivo em condição de sertão paraibano.

Desta forma, objetivou-se comesta pesquisa, avaliar a emergência, crescimento e produção da mamoneira irrigada com águas de diferentes salinidades associada a doses crescentes de adubação nitrogenada.

\section{MATERIAL E MÉTODOS}

$\mathrm{O}$ experimento foi desenvolvido entre outubro de 2010 e fevereiro de 2011, sendo as plantas conduzidas em lisímetros (vasos) sob condições de campo na área experimental do Centro de Ciências e Tecnologia Agroalimentar (CCTA) da Universidade Federal de Campina Grande (UFCG), Pombal, PB, situada a 6048'16" S e $37^{\circ} 49^{\prime} 15^{\prime \prime} \mathrm{W}$, a uma altitude de $144 \mathrm{~m}$.

Os tratamentos foram aleatorizados em blocos em esquema fatorial $5 \times 5$, com três repetições, e resultaram da combinação do fator condutividade elétrica da água de irrigação (CEa) em cinco níveis $\left(0,4 ; 1,4 ; 2,4 ; 3,4\right.$ e $\left.4,4 \mathrm{dS} \mathrm{m}^{-1}\right)$ associados a cinco doses de adubação nitrogenada (50; 75; 100; 125 e 150\%) recomendada para ensaio em vaso (NOVAIS; NEVES; BARROS, 1991), onde na dose $100 \%$ aplicou-se $16,67 \mathrm{~g}$ de fosfato monoamônio (MAP) mais 4,44 g de uréia. A adubação nitrogenada foi parcelada em cinco vezes, em intervalos de onze dias a partir de 24 dias após o semeio (DAS).

As unidades experimentais foram dispostas em fileira simples espaçadas de $0,9 \mathrm{~m}$ entre fileiras e $0,7 \mathrm{~m}$ entre plantas dentro da fileira.

Obteve-se as águas de diferentes salinidades mediante a adição do cloreto de sódio $(\mathrm{NaCl})$ a água de abastecimento, cuja quantidade (C) foi determinada com base na equação de Richards (1954), sendo C $\left(\mathrm{mg} \mathrm{L}^{-1}\right)=640$ x CEa $\left(\mathrm{dS} \mathrm{m}^{-1}\right)$, levando-se em consideração a $\mathrm{CEa}$. As águas com distintas condutividades elétricas foram acondicionadas em tonéis plásticos de 200 L de capacidade. 
Utilizou-se a cultivar 'BRS Energia' de mamoneira, onde conforme Milani (2010), este material genético possui ciclo de 120 a 150 dias, frutos semi-indeiscentes, teor de óleo nas sementes em média de $48 \%$ e produtividade média de $1.800 \mathrm{~kg} \mathrm{ha}^{-1}$.

Utilizou-se nesta pesquisa, lisímetros de drenagem com $100 \mathrm{~L}$ de capacidade, preenchidos com $2,0 \mathrm{~kg}$ de brita ( $\mathrm{n}^{\mathrm{o}}$ zero) a qual cobria a base do lisímetro, mais $107,8 \mathrm{~kg}$ de material de solo (tipo areia franca) não salino e não sódico, devidamente destorroado e proveniente do Município de Pombal, PB, cujas características físicoquímicas (Tabela 1) foram determinadas no Laboratório de Solos e Nutrição de Plantas do CCTA/UFCG, segundo metodologia proposta pela Empresa Brasileira de Pesquisa Agropecuária (1997). Na parte inferior de cada lisímetro existiam furos para permitir a drenagem e abaixo dos mesmos um microtubo (1 cm de diâmetro) conectando sua base a uma garrafa plástica (2,0 L de capacidade) para acompanhamento do volume drenado e consumo de água pela cultura.

Tabela 1 - Características físicas e químicas do solo utilizado no experimento

\begin{tabular}{lc}
\hline \multicolumn{1}{c}{ Característica } & Valor \\
\hline Classificação textural & Areia Franca \\
Densidade aparente $-\mathrm{kg} \mathrm{dm}^{-3}$ & 1,31 \\
Porosidade - \% & 48,22 \\
\multicolumn{2}{c}{ Complexo sortivo - $\mathrm{cmol}_{\mathrm{c}} \mathrm{kg}^{-1}$} \\
Cálcio $\left(\mathrm{Ca}^{2+}\right)$ & 7,50 \\
Magnésio $\left(\mathrm{Mg}^{2+}\right)$ & 5,15 \\
Sódio $\left(\mathrm{Na}^{+}\right)$ & 0,29 \\
Potássio $\left(\mathrm{K}^{+}\right)$ & 0,29
\end{tabular}

Extrato de saturação

\begin{tabular}{ll}
$\mathrm{pH}_{\mathrm{ps}}$ & 7,33 \\
$\mathrm{CE}_{\mathrm{es}}-\mathrm{dS} \mathrm{m}{ }^{-1}$ & 0,53 \\
Cloro $\left(\mathrm{Cl}^{-}\right)-\mathrm{mmol}_{\mathrm{c}} \mathrm{L}^{-1}$ & 3,75 \\
Carbonato $\left(\mathrm{CO}_{3}^{2-}\right)-\mathrm{mmol}_{\mathrm{c}} \mathrm{L}^{-1}$ & 0,00 \\
Bicarbonato $\left(\mathrm{HCO}_{3}^{-}\right)-\mathrm{mmol}_{\mathrm{c}} \mathrm{L}^{-1}$ & 2,00 \\
Sulfato $\left(\mathrm{SO}_{4}^{2-)}-\mathrm{mmol}_{\mathrm{c}} \mathrm{L}^{-1}\right.$ & 0,89 \\
Cálcio $\left(\mathrm{Ca}^{2+}\right)-\mathrm{mmol}_{\mathrm{c}} \mathrm{L}^{-1}$ & 1,87 \\
Magnésio $\left(\mathrm{Mg}^{2+}\right)-\mathrm{mmol}_{\mathrm{c}} \mathrm{L}^{-1}$ & 1,25 \\
Sódio $\left(\mathrm{Na}^{+}\right)-\mathrm{mmol}_{\mathrm{c}} \mathrm{L}^{-1}$ & 2,51 \\
Potássio $\left(\mathrm{K}^{+}\right)-\mathrm{mmol}_{\mathrm{c}} \mathrm{L}^{-1}$ & 0,49 \\
\hline
\end{tabular}

Realizou-se adubação básica aplicando-se 162,5 g de superfosfato simples, $12 \mathrm{~g}$ de sulfato de potássio e $2.200 \mathrm{~g}$ (equivalente a $2 \%$ ) de vermicomposto por vaso visando melhorar as propriedades físicas, químicas e biológicas do solo, aumentando a capacidade de retenção e infiltração de água no solo. O material de solo após ser acondicionado nos lisímetros foi colocado em capacidade de campo, conforme o método de saturação por capilaridade, seguida por drenagem livre e usando as distintas águas conforme tratamentos.

Em 28 de outubro de 2010 foi realizada a semeadura, colocando-se dez sementes por vaso a uma profundidade de $0,02 \mathrm{~m}$, sendo os vasos distribuídos em fileiras simples espaçados de 0,9 e $0,7 \mathrm{~m}$ entre plantas dentro da fileira. A emergência das plântulas iniciou no sexto dia após o semeio (DAS) e continuou até o décimo terceiro dia, sendo realizado aos 14 DAS o primeiro desbaste, deixando-se 4 plântulas por parcela, as que apresentavam melhor vigor. Aos 21, 35 e 46 DAS foram realizados novos desbastes onde se eliminou em cada um, uma planta por vaso.

Irrigou-se diariamente ao final de cada tarde $(17 \mathrm{~h})$, conforme tratamentos e com volume de água de $700 \mathrm{~mL}$ por vaso até o sexto dia após o semeio e posteriormente, aplicou-se um volume com base no balanço de água na zona radicular e considerando uma fração de lixiviação de $10 \%$.

Os tratos culturais realizados durante a condução resumiram-se em eliminação manual de plantas daninhas, tutoramento das plantas, escarificação superficial do solo antes de cada irrigação e visando o manejo preventivo de pragas e doenças foram realizadas pulverizações com produtos comerciais recomendados.

Foram realizadas duas adubações foliares a partir do início da emissão das flores, estádio $\mathrm{R}_{9}$ (MOSHKIN, 1986) aos 29 e 37 DAS, com Albatroz ( $\mathrm{N}-10 \%, \mathrm{P}_{2} \mathrm{O}_{5}-52 \%, \mathrm{~K}_{2} \mathrm{O}$ - $10 \%, \mathrm{Ca}-0,1 \%, \mathrm{Zn}-0,02 \%, \mathrm{~B}-0,02 \%, \mathrm{Fe}-0,15 \%, \mathrm{Mn}$ $-0,1 \%, \mathrm{Cu}-0,02 \%$ e Mo - 0,005\%) na proporção de $1 \mathrm{~g}$ do adubo para $1 \mathrm{~L}$ de água, aplicando-se $5 \mathrm{~L}$, distribuídos nas plantas, com auxilio de um pulverizador costal.

A emergência das plântulas foi avaliada mediante contagem diária, até os 13 DAS, do número de plântulas emergidas, usando-se como critério o surgimento do epicótilo na superfície do vaso, e daí determinou-se a porcentagem de emergência - PE (número de plântulas emergidas em relação ao número de sementes semeadas). Nessa mesma data avaliou-se o índice de velocidade de emergência (IVE), conforme Vieira e Carvalho (1994) (Equação 1).

$\operatorname{IVE}\left(\right.$ plântulas dia $\left.{ }^{-1}\right)=\frac{\sum_{N_{1}}}{+}+\frac{\sum_{N_{2}}}{2}+\ldots+\frac{\sum_{N n} n}{N n}$ 
em que, $\Sigma_{1}, \Sigma_{2}, \ldots \Sigma_{\mathrm{n}}$ representam os números de plântulas emergidas, computadas na primeira, segunda e última contagem e $\mathrm{N}_{1}, \mathrm{~N}_{2}, \ldots \mathrm{N}_{\mathrm{n}}$ são os números de dias da semeadura à primeira, segunda e última contagem, respectivamente.

Para análise do efeito dos tratamentos sobre o crescimento e produção da mamoneira foram mensurados aos 67 e 120 DAS, o número de folhas (NF), a altura de planta (AP) e o diâmetro do caule (DC); aos 120 DAS avaliou-se também, a fitomassa seca da parte aérea (FSPA) e de raízes (FSRaiz). Por ocasião da colheita foi mensurada a massa de sementes do racemo primário (MSemRP).

Na contagem do número de folhas consideraram-se as que estavam totalmente expandidas com comprimento mínimo de $3 \mathrm{~cm}$ e que apresentavam no mínimo $50 \%$ do seu tamanho fotossinteticamente ativa; a AP foi definida mensurando-se a distância entre o colo da planta e a inserção do racemo primário e o DC foi medido a $5 \mathrm{~cm}$ do colo da planta. Aos 120 DAS à haste de cada planta foi cortada rente ao solo, separando-se parte aérea de raízes, que após acondicionamento em sacos de papel devidamente identificados foram postos para secar em estufa de circulação forçada de ar, à $65^{\circ} \mathrm{C}$, até obtenção de massa constante para determinação da FSPA e FSRaiz.

A colheita do racemo primário foi realizada manualmente e teve início aos 72 DAS, ou seja, quando aproximadamente $90 \%$ dos frutos do racemo estavam secos, sendo o processo de secagem completado com a exposição dos mesmos ao sol. Na sequência, realizou-se a debulha manual dos frutos e determinou-se a MSemRP.

Os dados obtidos foram avaliados mediante análise de variância pelo teste ' $F$ ' ao nível de 0,05 de probabilidade e nos casos de significância, realizouse análise de regressão polinomial linear, quadrática e cúbica utilizando-se do software estatístico SISVARESAL (Lavras, MG) (FERREIRA, 2003). Em função da homogeneidade dos dados percebidos através dos baixos valores de coeficiente de variação (Tabela 2 e 3), não foi necessário realizar análise exploratória dos dados.

\section{RESULTADOS E DISCUSSÃO}

Observa-se na Tabela 2 que houve efeito significativo do fator níveis de salinidade da água de irrigação sobre a percentagem de emergência (PE), o índice de velocidade de emergência (IVE), o número de folhas (NF), a altura de planta (AP) e o diâmetro caulinar (DC) das plantas de mamoneira. Em relação ao fator doses de adubação nitrogenada assim como, na interação entre os fatores (salinidade da água de irrigação e doses de adubação nitrogenada), constatou-se haver efeito significativo apenas em relação à variável diâmetro do caule aos 67 e 120 DAS (Tabela 2), denotando que as doses de nitrogênio comportaram-se de maneira semelhante em diferentes níveis de salinidade da água utilizada na

Tabela 2 - Resumo da análise de variância para percentagem de emergência (PE), índice de velocidade de emergência (IVE), número de folhas (NF), altura de planta (AP) e diâmetro caulinar (DC) aos 67 e 120 dias após o semeio da mamoneira em função de diferentes níveis de salinidade da água de irrigação e doses de nitrogênio

\begin{tabular}{|c|c|c|c|c|c|c|c|c|}
\hline \multirow{3}{*}{ Fonte de Variação } & \multicolumn{8}{|c|}{ Quadrado Médio } \\
\hline & \multirow{2}{*}{ PE } & \multirow{2}{*}{ IVE } & \multicolumn{2}{|c|}{$\mathrm{NF}^{1}$} & \multicolumn{2}{|c|}{$\mathrm{AP}(\mathrm{cm})$} & \multicolumn{2}{|c|}{$\mathrm{DC}(\mathrm{mm})$} \\
\hline & & & 67 & 120 & 67 & 120 & 67 & 120 \\
\hline Níveis salino (S) & $548,1 * *$ & $0,09^{*}$ & $1782,7 * *$ & $1044,5^{* *}$ & $695,5 * *$ & $815,6^{* *}$ & $109,8 * *$ & $106,6^{* * *}$ \\
\hline Reg. Linear & $1377,5 * *$ & $0,32 * *$ & $6512,6^{* *}$ & $3512,0 * *$ & $2652,7 * *$ & $3010,3 * *$ & $422,1 * *$ & $403,7 * *$ \\
\hline Reg. Quadrática & $240,6^{\mathrm{ns}}$ & $0,01^{\mathrm{ns}}$ & $111,9^{\text {ns }}$ & $334,7^{\mathrm{ns}}$ & $5,2^{\mathrm{ns}}$ & $39,0^{\mathrm{ns}}$ & $1,0^{\mathrm{ns}}$ & $5,6^{\mathrm{ns}}$ \\
\hline Reg. Cúbica & $466,3^{*}$ & $0,01^{\mathrm{ns}}$ & $153,8^{\mathrm{ns}}$ & $252,8^{\mathrm{ns}}$ & $2,1^{\mathrm{ns}}$ & $1,6^{\mathrm{ns}}$ & $0,1^{\mathrm{ns}}$ & $6,3^{\mathrm{ns}}$ \\
\hline Doses nitrog. (D) & $21,3^{\mathrm{ns}}$ & $0,02^{\mathrm{ns}}$ & $138,9^{\text {ns }}$ & $216,0^{\mathrm{ns}}$ & $50,1^{\mathrm{ns}}$ & $43,6^{\mathrm{ns}}$ & $4,3^{*}$ & $10,4^{*}$ \\
\hline Reg. Linear & $42,7^{\mathrm{ns}}$ & $0,05^{\mathrm{ns}}$ & $12,9^{\mathrm{ns}}$ & $269,3^{\mathrm{ns}}$ & $53,3^{\mathrm{ns}}$ & $0,0^{\mathrm{ns}}$ & $15,1 * *$ & $37,8 * *$ \\
\hline Reg. Quadrática & $7,6^{\mathrm{ns}}$ & $0,00^{\mathrm{ns}}$ & $245,4^{\mathrm{ns}}$ & $156,0^{\mathrm{ns}}$ & $49,9^{\mathrm{ns}}$ & $31,2^{\mathrm{ns}}$ & $2,1^{\mathrm{ns}}$ & $0,9^{\mathrm{ns}}$ \\
\hline Reg. Cúbica & $10,7^{\text {ns }}$ & $0,01^{\mathrm{ns}}$ & $285,7^{\mathrm{ns}}$ & $185,9^{\text {ns }}$ & $9,7^{\mathrm{ns}}$ & $32,2^{\text {ns }}$ & $0,0^{\mathrm{ns}}$ & $1,3^{\mathrm{ns}}$ \\
\hline Interação (S x D) & $119,6^{\mathrm{ns}}$ & $0,03^{\mathrm{ns}}$ & $117,7 \mathrm{~ns}$ & $99,5^{\mathrm{ns}}$ & $12,9^{\text {ns }}$ & $16,8^{\mathrm{ns}}$ & $3,2 * *$ & $6,2^{*}$ \\
\hline Bloco & $52,0^{\text {ns }}$ & $0,05^{\text {ns }}$ & $11,5^{\text {ns }}$ & $254,0^{\text {ns }}$ & $94,3^{\text {ns }}$ & $77,6^{\text {ns }}$ & $0,1^{\text {ns }}$ & $0,9^{\mathrm{ns}}$ \\
\hline $\mathrm{CV}(\%)$ & 9,67 & 13,92 & 17,01 & 29,22 & 8,45 & 8,44 & 6,03 & 8,34 \\
\hline
\end{tabular}

$\mathrm{ns}, * *, *$ respectivamente não significativo, significativo a $\mathrm{p}<0,01 \mathrm{e} \mathrm{p}<0,05 ;{ }^{1}$ análise estatística realizada após transformação de dados em $\sqrt{\mathrm{X}}$ 
irrigação para as variáveis NF e AP, nas duas épocas de avaliação.

A salinidade da água de irrigação afetou significativamente $(\mathrm{p}<0,01)$ a percentagem de emergência e o índice de velocidade de emergência $(\mathrm{p}<0,05)$ (Tabela 2). Conforme equações de regressão (Figura $1 \mathrm{~A}$ e 1B), constata-se que o aumento da condutividade elétrica da água de irrigação reduziu linearmente a PE e o IVE, promovendo respectivamente, decréscimos na ordem de $3,35 \%$ e $3,62 \%$ por aumento unitário da CEa, ou seja, redução de $13,4 \%$ na $\mathrm{PE}$ e de $14,48 \%$ no IVE das plantas irrigadas com água de $4,4 \mathrm{dS}$ $\mathrm{m}^{-1}$, em relação à testemunha, evidenciando que o estresse salino além de reduzir o percentual de emergência das plântulas, retarda sua emergência. De acordo com Rhoades e Loveday (1990) a influência significativa da CEa tanto no índice de velocidade de emergência como na percentagem de emergência, está relacionada à redução do potencial osmótico da solução do solo, causado pelo aumento da concentração de sais solúveis; isto resulta em diminuição da absorção de água pela semente e em consequência, contribui para decréscimo na percentagem de germinação, além de atraso na germinação.

Silva et al. (2005) avaliando o comportamento de duas cultivares de mamona (R. communis L.), BRS-188 Paraguaçu e CSRN-367, irrigadas com águas de diferentes níveis salinos (CEa de 0,7 a $8,7 \mathrm{dS} \mathrm{m}^{-1}$ ) verificaram também, que a percentagem de emergência e o índice de velocidade de emergência diminuíram linearmente com o aumento da CEa. Diferentemente, Cavalcanti et al. (2005a) ao estudarem a influência da salinidade da água na germinação da mamoneira BRS 149 - Nordestina, constataram que a
CEa de até 4,7 dS m ${ }^{-1}$ não influenciou a percentagem de emergência, o que denota ser esta cultivar mais tolerante aos sais na fase de germinação em relação a BRS Energia.

O número de folhas da mamoneira sofreu efeito significativo $(\mathrm{p}<0,01)$ da salinidade da água (Tabela 2) e segundo equações de regressão (Figura 2A) o modelo linear indica decréscimos do NF aos 67 e 120 DAS, respectivamente de $16,69 \%$ e $13,98 \%$ por aumento unitário da CEa, ou seja, redução de 26,57 (66,74\%) e $19,52(55,33 \%)$ folhas na primeira e segunda data de avaliação, quando se comparam as plantas irrigadas com água de 4,4 $\mathrm{dS} \mathrm{m}^{-1}$ com as de $0,4 \mathrm{dS} \mathrm{m}^{-1}$. Corroborando com os resultados obtidos, Silva et al. (2008a) estudando o comportamento da mamoneira 'BRS Energia' irrigada com águas de diferentes salinidades $\left(0,7\right.$ a $\left.6,7 \mathrm{dS} \mathrm{m}^{-1}\right)$ e em condição de ambiente protegido, observaram reduções no NF de $7,50 \%$ e $12,02 \%$ por aumento unitário da CEa, respectivamente, aos 80 e 100 DAS. Fageria (1989) relata que, decréscimos no número de folhas quando as plantas são cultivadas sob estresse salino, ocorrem como forma de adaptação, no sentido de minimizar as perdas de água por transpiração.

O fator salinidade da água de irrigação influenciou significativamente $(\mathrm{p}<0,01)$ a altura de plantas (AP) da mamoneira 'BRS Energia' aos 67 e 120 DAS (Tabela 2). De acordo com as equações de regressão (Figura 2B), verifica-se resposta linear decrescente da AP ao incremento da $\mathrm{CEa}$, ocorrendo respectivamente, aos 67 e 120 DAS, decréscimos na ordem de $6,22 \%(16,72 \mathrm{~cm})$ e $6,15 \%(17,86 \mathrm{~cm})$ na AP por aumento unitário da CEa. Segundo Arruda et al. (2002) plantas cultivadas sob estresse salino podem

Figura 1 - Percentagem de emergência (A) e Índice de velocidade de emergência - IVE (B) da mamoneira, em função da condutividade elétrica da água de irrigação (CEa)
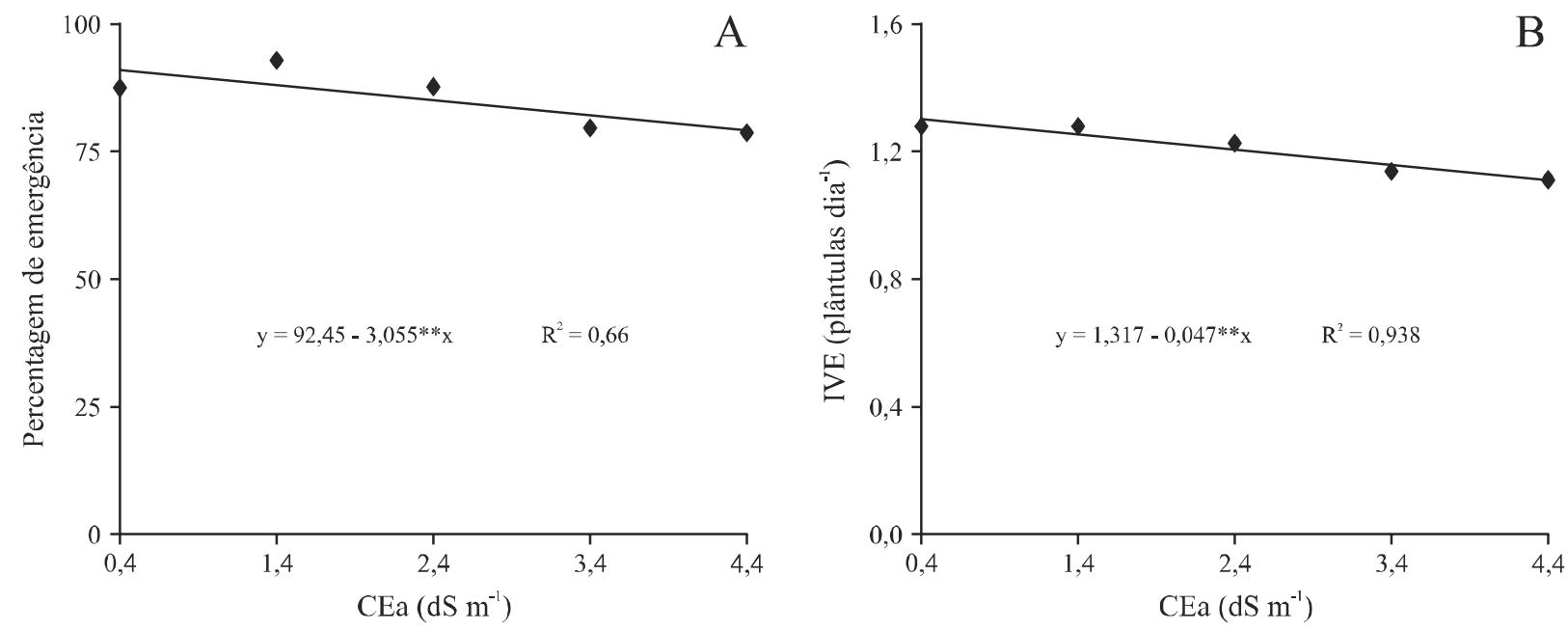
Figura 2 - Número de folhas (A) e altura de planta (B) da mamoneira, em função da condutividade elétrica da água de irrigação (CEa) aos 67 e 120 dias após o semeio (DAS)

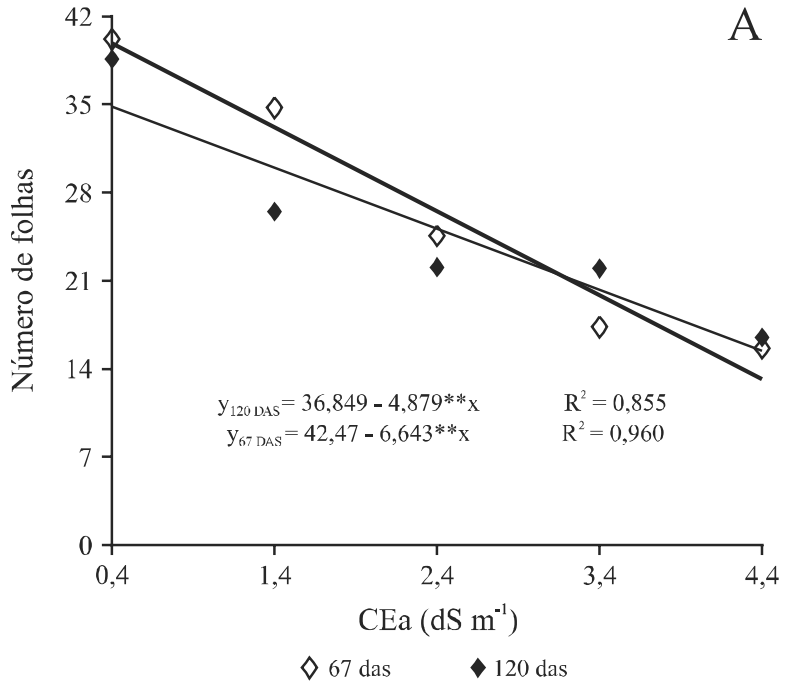

ter o crescimento inibido devido aos efeitos tóxicos dos sais absorvidos ou pela baixa capacidade de ajustamento osmótico da cultura, que tendem a reduzir a quantidade de água e nutrientes absorvidos e como consequência, a capacidade das plantas crescerem e desenvolverem é afetada negativamente.

Os efeitos do estresse salino obtidos neste estudo são condizentes com os encontrados por Cavalcanti et al. (2005b), em pesquisa a mamoneira 'BRS Nordestina' irrigada com águas de CEa variando de 0,7 a 4,7 dS m m $^{-1}$ onde verificaram já aos 30 DAS, redução da AP de 5,85\% por aumento unitário da CEa. Conforme Yahya (1998) a maior causa da redução do crescimento das plantas esta associado ao efeito osmótico e ao desequilíbrio nutricional provocado pelo excesso de sais, principalmente de sódio e cloro.

Constata-se na Tabela 2, que a interação entre os fatores (salinidade da água de irrigação e doses de nitrogênio) teve efeito significativo $(\mathrm{p}<0,01)$ sobre o diâmetro do caule aos 67 e 120 DAS ( $p<0,05)$. Aos 67 DAS verifica-se com base nas equações de regressão (Figura 3A) haver comportamento linear decrescente no DC das plantas submetidas à adubação com 50; 75; 100; 125 e $150 \%$ de N, cujos decréscimos foram respectivamente de 5,$91 ; 6,27 ; 9,36 ; 7,55$ e 9,68\% por incremento unitário da CEa ou seja, redução de 4,68; 5,17; 8,53; 6,64; 8,89 $\mathrm{mm}$ no DC das plantas irrigadas com CEa de 4,4 $\mathrm{dS} \mathrm{m}^{-1}$ em relação às sob CEa de $0,4 \mathrm{dS} \mathrm{m} \mathrm{m}^{-1}$. Verifica-se (Figura 3A) que o incremento salino promoveu decréscimos no DC das plantas adubadas com doses crescentes de $\mathrm{N}$, entretanto, nota-se que quando se submeteram as

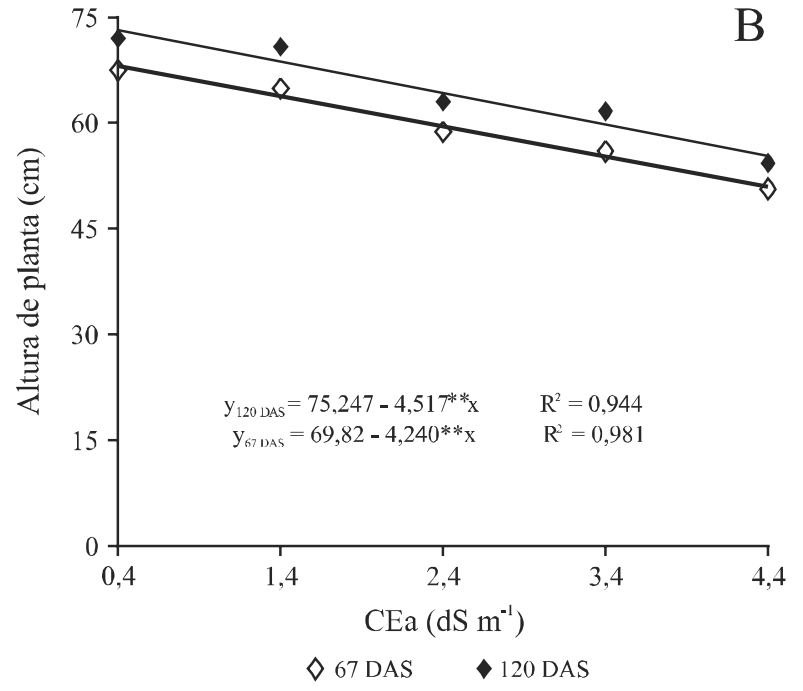

plantas a níveis salinos a partir de $2,4 \mathrm{dS} \mathrm{m}^{-1}$, as que estavam sob adubação de $125 \%$ de N, tiveram os maiores DC. Flores et al. (2001) destacam que a fertilização nitrogenada além de promover o crescimento das plantas, pode também reduzir o efeito da salinidade nos vegetais.

Conforme equações de regressão referente ao diâmetro do caule aos 120 DAS (Figura 3B), observa-se decréscimos linear por aumento unitário da CEa na ordem de 4,$17 ; 4,25 ; 8,70 ; 7,85$ e $8,72 \%$ no DC das plantas submetidas respectivamente, a doses de nitrogênio de 50; $75 ; 100 ; 125$ e $150 \%$, ou seja, o DC das plantas sob irrigação com níveis de salinidade de 4,4 $\mathrm{dS} \mathrm{m}^{-1}$ decresceram 3,65; 3,$76 ; 8,65 ; 8,07$ e 9,47 mm, em relação às plantas irrigadas com CEa de $0,4 \mathrm{dS} \mathrm{m}^{-1}$. Apesar dos maiores decréscimos do DC em função do incremento salino, terem sido verificados nas plantas que receberam doses superiores de N (100; 125 e 150\%), que independente no nível salino, os maiores diâmetros foram obtidos quando submeteram-se as plantas a doses de $\mathrm{N}$ de 150 e $125 \%$ (Figura 3B).

Conforme análise de variância (Tabela 3 ) houve efeito significativo $(\mathrm{p}<0,01)$ dos níveis salinos da água de irrigação $(\mathrm{S})$ sobre a fitomassa seca da parte área (FSPA) e de raiz (FSRaiz) aos 120 DAS e na massa de sementes do racemo primário (MSemRP). O fator adubação nitrogenada (D) promoveu efeito significativo $(\mathrm{p}<0,05)$ sobre a FSPA e FSRaiz, assim como, constata-se efeito $(\mathrm{p}<0,05)$ da interação entre os fatores (S x D) sobre a FSRaiz. 
Níveis crescentes da salinidade da água de irrigação afetaram a fitomassa seca da parte aérea (FSPA), e conforme equações de regressão (Figura 4A) verifica-se que o modelo ao qual os dados melhor se ajustaram foi o linear, ocorrendo decréscimos na FSPA de 15,63\% por aumento unitário da CEa, sendo constatado aos 120 DAS, nas plantas irrigadas com água de $4,4 \mathrm{dS}$ $\mathrm{m}^{-1}$ redução da FSPA de 45,44 $\mathrm{g}$ planta $^{-1}(62,52 \%) \mathrm{em}$ relação às plantas sob irrigação com água de $0,4 \mathrm{dS} \mathrm{m}^{-1}$.
O efeito do estresse salino aos 120 DAS sobre a FSPA da mamoneira foi expressivo, mostrando a fragilidade da cultura aos sais, principalmente com o aumento do tempo de exposição, pois conforme Campos et al. (2009) a mamoneira demonstra ser afetada pela CEa desde a fase de crescimento inicial onde, constataram aos 30 DAS, que as plantas da cv. BRS Paraguaçu tiveram redução de $2,01 \%$ da FSPA por incremento unitário da CEa.

Figura 3 - Diâmetro do caule da mamoneira em função da condutividade elétrica da água de irrigação (CEa) e doses de nitrogênio aos 67 (A) e 120 (B) dias após o semeio (DAS)
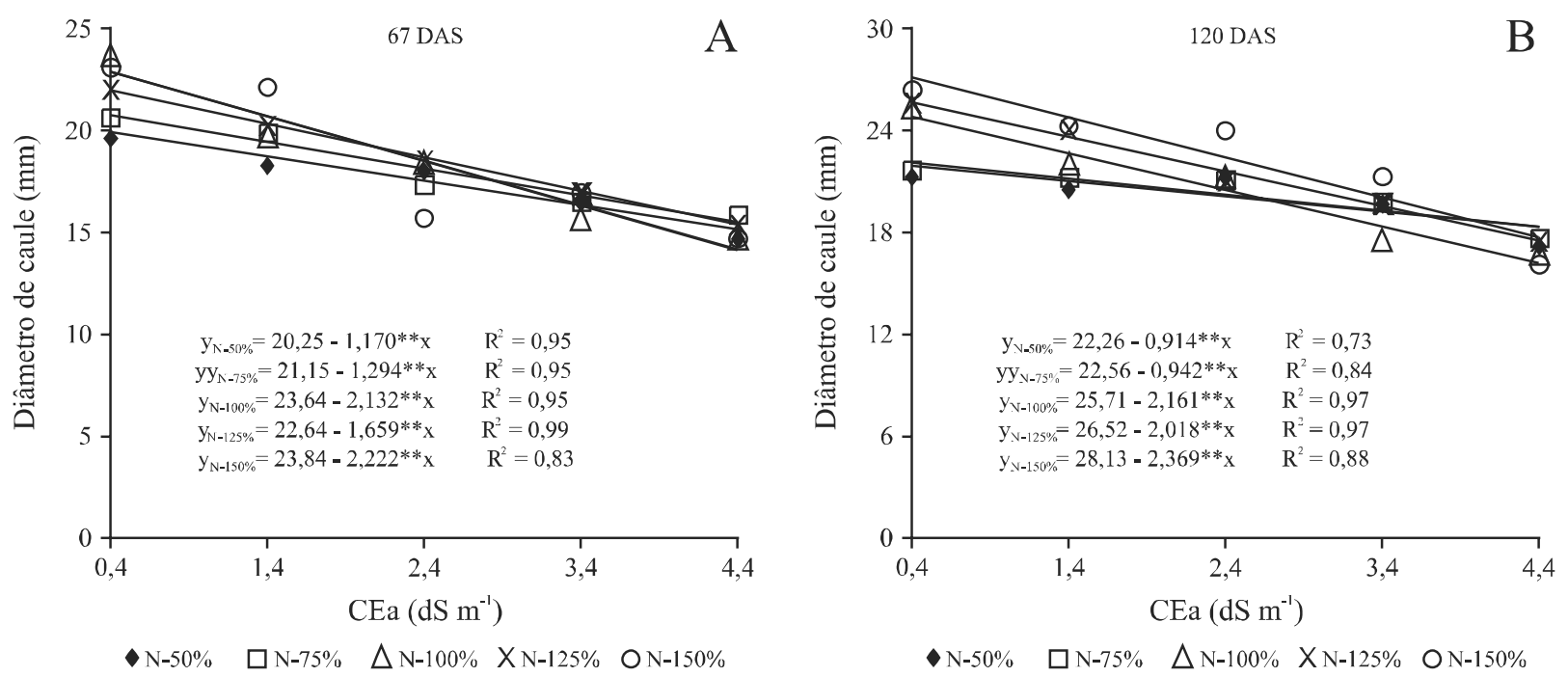

Tabela 3 - Resumo do teste de F para fitomassa seca da parte aérea (FSPA) e de raiz (FSRaiz) aos 120 DAS e massa de sementes do racemo primário (MSemRP) da mamoneira em função de diferentes níveis de salinidade da água de irrigação e doses de nitrogênio

\begin{tabular}{|c|c|c|c|}
\hline \multirow{2}{*}{ Fonte de Variação } & \multicolumn{3}{|c|}{ Teste F } \\
\hline & FSPA $^{1}$ & FSRaiz $^{1}$ & $\mathrm{MSemRP}^{2}$ \\
\hline Níveis salino (S) & $5.104,63 * *$ & $575,64 * *$ & $4.339,84 * *$ \\
\hline Reg. Linear & $19.038,87 * *$ & $2.063,36 * *$ & $1.4684,73 * *$ \\
\hline Reg. Quadrática & $0,54^{\mathrm{ns}}$ & $29,85^{\mathrm{ns}}$ & $2.035,92 *$ \\
\hline Reg. Cúbica & $870,78 * *$ & $110,65^{*}$ & $6,27^{\mathrm{ns}}$ \\
\hline Doses nitrogênio (D) & $350,50 *$ & $83,26^{*}$ & $363,26^{\mathrm{ns}}$ \\
\hline Reg. Linear & $1.316,43 * *$ & $237,35 * *$ & $0,16^{\mathrm{ns}}$ \\
\hline Reg. Quadrática & $28,80^{\mathrm{ns}}$ & $36,01^{\mathrm{ns}}$ & $967,20^{\mathrm{ns}}$ \\
\hline Reg. Cúbica & $14,51^{\mathrm{ns}}$ & $59,56^{\mathrm{ns}}$ & $50,64^{\mathrm{ns}}$ \\
\hline Interação (S x D) & $170,38^{\mathrm{ns}}$ & $56,74 *$ & $236,73^{\mathrm{ns}}$ \\
\hline Bloco & $79,964^{\text {ns }}$ & $20,68^{\mathrm{ns}}$ & $320,24^{\mathrm{ns}}$ \\
\hline $\mathrm{CV}(\%)$ & 11,64 & 20,75 & 24,61 \\
\hline
\end{tabular}

ns, **, * respectivamente não significativo, significativo a p $<0,01$ e p $<0,05 ;{ }^{1}$ análise estatística realizada após transformação de dados em $\sqrt{ } \mathrm{X} ;{ }^{2}$ análise estatística realizada após transformação de dados em $\sqrt{ } \mathrm{X}+1$ 
Figura 4 - Fitomassa seca da parte aérea (FSPA) da mamoneira, em função da condutividade elétrica da água de irrigação - CEa (A) e doses de nitrogênio (B), aos 120 dias após o semeio

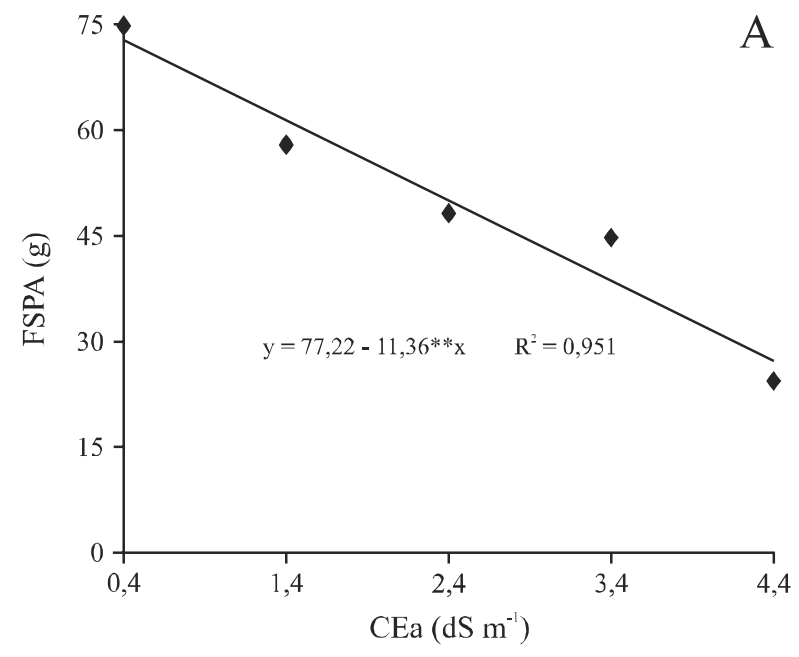

Denota-se que o incremento da $\mathrm{CEa}$ tenha reduzido a disponibilidade de água para as plantas e consequentemente, a produção de matéria seca tenha sido comprometida. Segundo Hasegawa et al. (2000), plantas cultivadas sob estresse salino, absorvem menos água devido terem menor capacidade de ajustamento osmótico e, como consequência, tem seu crescimento e desenvolvimento prejudicado; Barros Júnior et al. (2008) em estudo com cultivares de mamoneira 'BRS Nordestina e BRS Paraguaçu' verificaram que as plantas conduzidas a nível de $100 \%$ de água disponível (AD) no solo superaram, em 3,4 vezes em termos de fitomassa seca, as plantas que foram mantidas em parcelas com $60 \%$ de AD.

Em relação ao efeito da adubação nitrogenada sobre a FSPA aos 120 DAS, observa-se segundo modelos estatísticos (Figura 4B) que as doses crescentes de N, promoveram acréscimos de 21,19\% (12,47 $\left.\mathrm{g}_{\text {planta }}^{-1}\right)$ na FSPA das plantas sob $150 \%$ de $\mathrm{N}$ em relação às com $50 \%$ de $\mathrm{N}$, ou seja, incremento de $5,30 \%$ por intervalo de $25 \%$ da dose de adubação nitrogenada estudada. Estes resultados são condizentes com relatos de Chaves, Gheyi e Ribeiro (2011) que ao analisarem o efeito da adubação nitrogenada sobre a produção de fitomassa e o consumo de água da mamoneira, constataram aumento destas variáveis com a elevação das doses de nitrogênio, indicando elevada eficiência na transformação da água consumida em matéria seca.

A interação entre os fatores (salinidade da água de irrigação e doses de nitrogênio) afetou a fitomassa seca de raiz (FSRaiz) e, de acordo com as equações de regressão (Figura 5A), vê-se efeito linear decrescente nas plantas submetidas à adubação com 50; 75; 100; 125

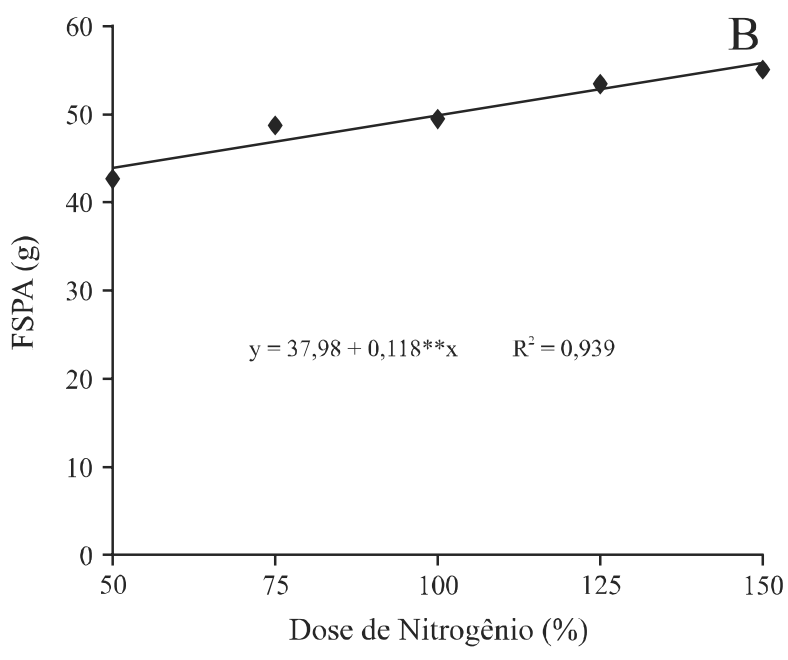

e $150 \%$ de $\mathrm{N}$, cujos decréscimos foram respectivamente de 14,$04 ; 16,05 ; 20,15 ; 17,03$ e $20,90 \%$ na FSRaiz por incremento unitário da CEa ou seja, redução de 56,16 $(8,32 \mathrm{~g}) ; 64,21$ (11,82 g); 80,61 (16,45 g); 68,13 (12,92 g) e $83,60 \%$ (25,86 g) na FSRaiz das plantas irrigadas com CEa de $4,4 \mathrm{dS} \mathrm{m}^{-1}$ em relação as sob CEa de $0,4 \mathrm{dS} \mathrm{m}^{-1}$. Ayers e Westcot (1999) relatam que, à medida que a salinidade do solo aumenta a disponibilidade de água para a cultura diminui, pois a planta passa a necessitar de mais energia para absorver a água do solo, diminuindo o seu crescimento, em termos de parte aérea e raízes.

Observa-se na Figura 5A que o aumento dos níveis salinos promoveu decréscimos no DC das plantas adubadas com distintas doses de $\mathrm{N}$, entretanto, nota-se que com exceção das plantas irrigadas com CEa de 4,4 dS m ${ }^{-1}$, quando forneceu a dose de $150 \%$ de nitrogênio foi possível obter as maiores massas de raízes. Tal efeito pode ser atribuído às funções do ' $\mathrm{N}$ ' nas plantas, uma vez que desempenha função estrutural, fazendo parte de diversos compostos orgânicos vitais para o vegetal, além do que, estudos têm demonstrado que o acúmulo desses solutos orgânicos eleva a capacidade de ajustamento osmótico das plantas à salinidade, e aumenta a resistência das culturas ao estresse hídrico e salino (SILVA et al., 2008b).

Campos et al. (2009), em estudos avaliando os efeitos da salinidade da água de irrigação (CEa de 0,5 a 6,0 $\mathrm{dS} \mathrm{m}^{-1}$ ) e do biofertilizante bovino no crescimento inicial da mamoneira cv. BRS Paraguaçu constataram que a biomassa das raízes foram superiores nos tratamentos com biofertilizante bovino, independente dos níveis de CEa. 
Figura 5 - Fitomassa seca de raiz (FSRaiz) aos 120 dias após o semeio (DAS) em função da condutividade elétrica da água de irrigação - CEa e doses de nitrogênio (A) e Massa de sementes do racemo primário (MSemRP) (B) da mamoneira, em função da CEa

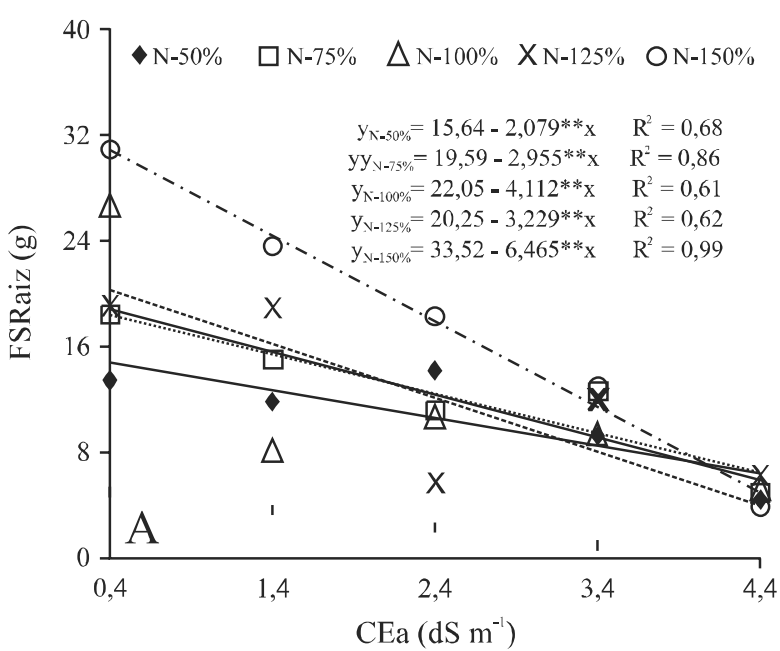

Para a variável massa de sementes do racemo primário(MSemRP) cujocomportamentofoidescrito por uma equação de regressão linear (Figura 5B), verificase redução de $19,27 \%$ por aumento unitário da CEa. Analisando-se o comportamento desta característica, nota-se decréscimo de 77,07\% $(39,49 \mathrm{~g})$ entre o maior $\left(\mathrm{CEa}=4,4 \mathrm{dS} \mathrm{m}^{-1}\right)$ e o menor $\left(\mathrm{CEa}=0,4 \mathrm{dS} \mathrm{m}^{-1}\right)$ nível de salinidade da água de irrigação, podendo-se inferir que o aumento da salinidade da água de irrigação tem interferência direta no acúmulo de massa de sementes do racemo primário. Gulzar, Khan e Ungar (2003) relatam que, os estresses provocados pelo excesso de íons, em geral, diminuem a assimilação de $\mathrm{CO}_{2}$, condutância estomática, transpiração e fotossíntese das plantas e, consequentemente, acabam por prejudicar a produção das culturas. Efeito do estresse salino sobre variáveis de produção foi observado também por Silva et al. (2008a), estudando o efeito da CEa (0,7 a 6,7 $\left.\mathrm{dS} \mathrm{m}^{-1}\right)$ sobre a produção de cultivares de mamoneira (BRS Energia e BRS Paraguaçu) onde constataram que acima de $4,7 \mathrm{dS} \mathrm{m}^{-1}$ as plantas não frutificaram e que o incremento salino reduziu em $96,8 \%$ a massa sementes do racemo primário das plantas sob CEa de $4,7 \mathrm{dS} \mathrm{m}^{-1}$ em comparação às sob CEa de $0,7 \mathrm{dS} \mathrm{m}{ }^{-1}$.

\section{CONCLUSÕES}

1. A partir da salinidade da água de irrigação de $0,4 \mathrm{dS}$ $\mathrm{m}^{-1}$ houve decréscimos linear da percentagem de emergência, do índice de velocidade de emergência, da altura de planta, do diâmetro caulinar, da fitomassa

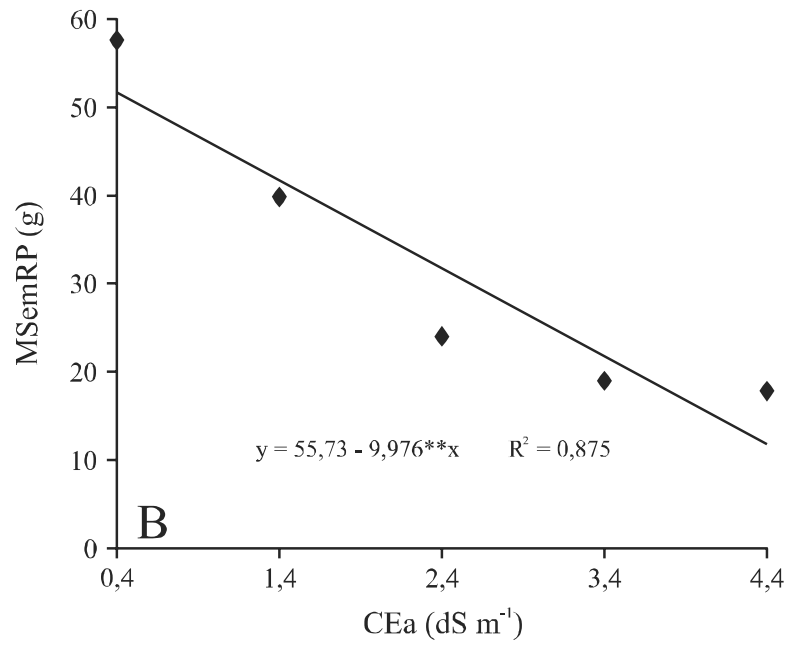

seca da parte aérea e de raiz e da massa de sementes do racemo primário da mamoneira cv. BRS Energia;

2. A massa de sementes do racemo primário é a variável mais sensível ao estresse salino, ocorrendo redução de 19,3\% por aumento unitário da $\mathrm{CEa}$;

3. Doses crescentes de adubação nitrogenada reduziram o efeito da salinidade sobre o diâmetro de caule e fitomassa seca de raiz da mamoneira cv. BRS Energia além, de terem proporcionado aumento no DC, na FSPA e na FSRaiz, sendo os melhores resultados obtidos com doses de nitrogênio de $150 \%$.

\section{AGRADECIMENTOS}

Ao Conselho Nacional de Pesquisa e Desenvolvimento - CNPq, pela concessão do auxílio financeiro (Projeto Universal) e bolsa PIBIC; e à Embrapa Algodão, pelo fornecimento das sementes de mamona.

\section{REFERÊNCIAS}

ARRUDA, F. P. de. et al. Efeito do estresse hídrico na emissão/ abscisão de estruturas reprodutivas do algodoeiro herbáceo cv. CNPA 7H. Revista Brasileira de Engenharia Agrícola e Ambiental, v. 6, n. 01, p. 21-27, 2002.

AYERS, R. S.; WESTCOT, D. W. A qualidade da água na agricultura. Campina Grande: UFPB, 1999. 218 p. (Irrigação e Drenagem, 29). 
BARROS JUNIOR, G. et al. Consumo de água e eficiência do uso para duas cultivares de mamona submetidas a estresse hídrico. Revista Brasileira de Engenharia Agrícola e Ambiental, v. 12, n. 04, p. 350-355, 2008.

BELTRÃO, N. E. M. et al. Zoneamento e época de plantio da mamoneira para o Nordeste brasileiro com aptidão sem restrições. Campina Grande: Embrapa Algodão, 2003. (Comunicado Técnico, 193).

CAMPOS, V. B. et al. Crescimento inicial da mamoneira em resposta à salinidade e biofertilizante bovino. Magistra, v. 21, n. 01, p. 041-047, 2009.

CAVALCANTI, M. L. F. et al. Tolerância da mamoneira BRS 149 à salinidade: germinação e características de crescimento. Revista Brasileira de Engenharia Agrícola e Ambiental, v. 09, p. 57-61, 2005a. Suplemento.

CAVALCANTI, M. L. F. et al. Índices ecofisiológicos da mamoneira sob estresse salino. Revista Brasileira de Engenharia Agrícola e Ambiental, v. 09, p. 66-70, 2005b. Suplemento.

CHAVES, L. H. G.; GHEYI, H. R.; RIBEIRO, S. Consumo de água e eficiência do uso para cultivar de mamona Paraguaçu submetida à fertilização nitrogenada. Revista de Engenharia Ambiental, v. 08, n. 01, p. 126-133, 2011.

DINIZ NETO, M. A. et al. Adubação NPK e épocas de plantio para mamoneira. I - Componentes da produção e produtividade. Revista Ciência Agronômica, v. 40, n. 04, p. 578-587, 2009.

EMPRESABRASILEIRA DE PESQUISAAGROPECUÁRIA BRASILEIRA. Manual e métodos de análise de solo. 2. ed. Rio de Janeiro: Centro Nacional de Pesquisa de Solos, 1997. $212 \mathrm{p}$.

FAGERIA, N. K. Solos tropicais e aspectos fisiológicos das culturas. Brasília: EMBRAPA- DPU, 1989. 425 p. (Documentos, 18).

FERREIRA, D. F. Sistema de análises estatísticas. Lavras: UFLA, 2003. $32 \mathrm{p}$.

FLORES, P. et al. Salinity and ammonium/nitrate interactions on tomato plant development, nutrition, and metabolites. Journal of Plant Nutrition, v. 24, n. 10, p. 1561-1573, 2001.

GULZAR, S.; KHAN, M. A.; UNGAR, I. A. Salt tolerance of a coastal salt marsh grass. Soil Science and Plant Analysis, v. 34, n. 17 , p. 2595-2605, 2003.

HASEGAWA, P. et al. Plant cellular and molecular responses to high salinity. Annual Review Plant Physiology and Plant Molecular Biology, v. 51, p. 463-499, 2000.

KAFKAFI, U. Plant nutrition under saline conditions. In: SHAINBERG, I; SHALHEVET, J. (Ed.). Soil salinity under irrigation: processes and management. Berlin: Springer-Verlag, p. 319-338, 1984.

MARINHO, A. B. et al. Influência da fertirrigação da nitrogenada na produtividade da cultura da mamoneira. Revista Brasileira de Agricultura Irrigada, v. 04, n. 01, p. 31-42, 2010.
MEDEIROS, J. F. et al. Caracterização das águas usadas para irrigação na área produtora de melão da Chapada do Apodi. Revista Brasileira de Engenharia Agrícola e Ambiental, v. 07, n. 04, p. 469-472, 2003.

MILANI, M. BRS Energia. 3. ed. Campina Grande - PB: Embrapa Algodão, 2010. Folder

MILLER, A. J.; CRAMER, M. D. Root nitrogen acquisition and assimilation. Plant and Soil, v. 274, n. 01, p. 03-06, 2004.

MOSHKIN, V. A. Growth and development of the plant. In: MOSHKIN, V. A. (Ed.). Castor. New Delhi: Amerind, 1986.

MUNNS, R. Genes and salt tolerance: bringing them together. New Phytologist, v. 167, n. 03, p. 645-663, 2005.

NEVES, A. L. R. et al. Acumulação de biomassa e extração de nutrientes por plantas de feijão-de-corda irrigadas com água salina em diferentes estádios de desenvolvimento. Ciência Rural, v. 39, n. 03, p. 758-765, 2009.

NOVAIS, R. F.; NEVES J. C. L.; BARROS N. F. Ensaio em ambiente controlado. In: OLIVEIRA A. J. (Ed.) Métodos de pesquisa em fertilidade do solo. Brasília: Embrapa-SEA, 1991. p. 189-253.

RHOADES, J. D.; LOVEDAY, J. Salinity in irrigated agriculture. In: STEWARD, B. A.; NIELSEN, D. R. (Ed.). Irrigation of agricultural crops. Madison: American Society Agronomy, 1990. cap. 9, p. 31-67. Agronomy, 30.

RICHARDS, L. A. Diagnosis and improvement of saline and alkali soils. Washington: U.S, Department of Agriculture, 1954. 160 p. Handbook 60

SILVA, E. C. et al. Physiological responses to salt stress in young umbu plants. Environmental and Experimental Botany, v. 63, n. $01 / 03$, p. $147-157,2008$ b.

SILVA, J. V. et al. Physiological responses of $\mathrm{NaCl}$ stressed cowpea plants grown in nutrient solution supplemented with $\mathrm{CaCl}_{2}$. Brazilian Journal of Plant Physiology, v. 15, n. 02, p. 99-105, 2003.

SILVA, S. M. S. et al. Germinação e crescimento inicial de duas cultivares de mamoneira sob estresse salino. Revista Brasileira de Engenharia Agrícola e Ambiental, v. 09, p. 347-352, 2005. Suplemento.

SILVA, S. M. S. et al. Desenvolvimento e produção de duas cultivares de mamoneira sob estresse salino. Revista Brasileira de Engenharia Agrícola e Ambiental, v. 12, n. 04, p. 335-342, 2008 a.

VIÉGAS, R. A. et al. Plant growth, accumulation and solute partitioning of four forest species under salt stress. Revista Brasileira de Engenharia Agrícola e Ambiental, v. 07, n. 02, p. 258-262, 2003 .

VIEIRA, R. D.; CARVALHO, N. M. Teste de vigor em sementes. Jaboticabal: FUNEP/UNESP-FCAVJ, 1994. 164 p.

YAHYA, A. Salinity effects on growth and on uptake and distribution of sodium and some essential mineral nutrients in sesame. Journal of Plant Nutrition, v. 21, n. 07, p. 14391451, 1998. 